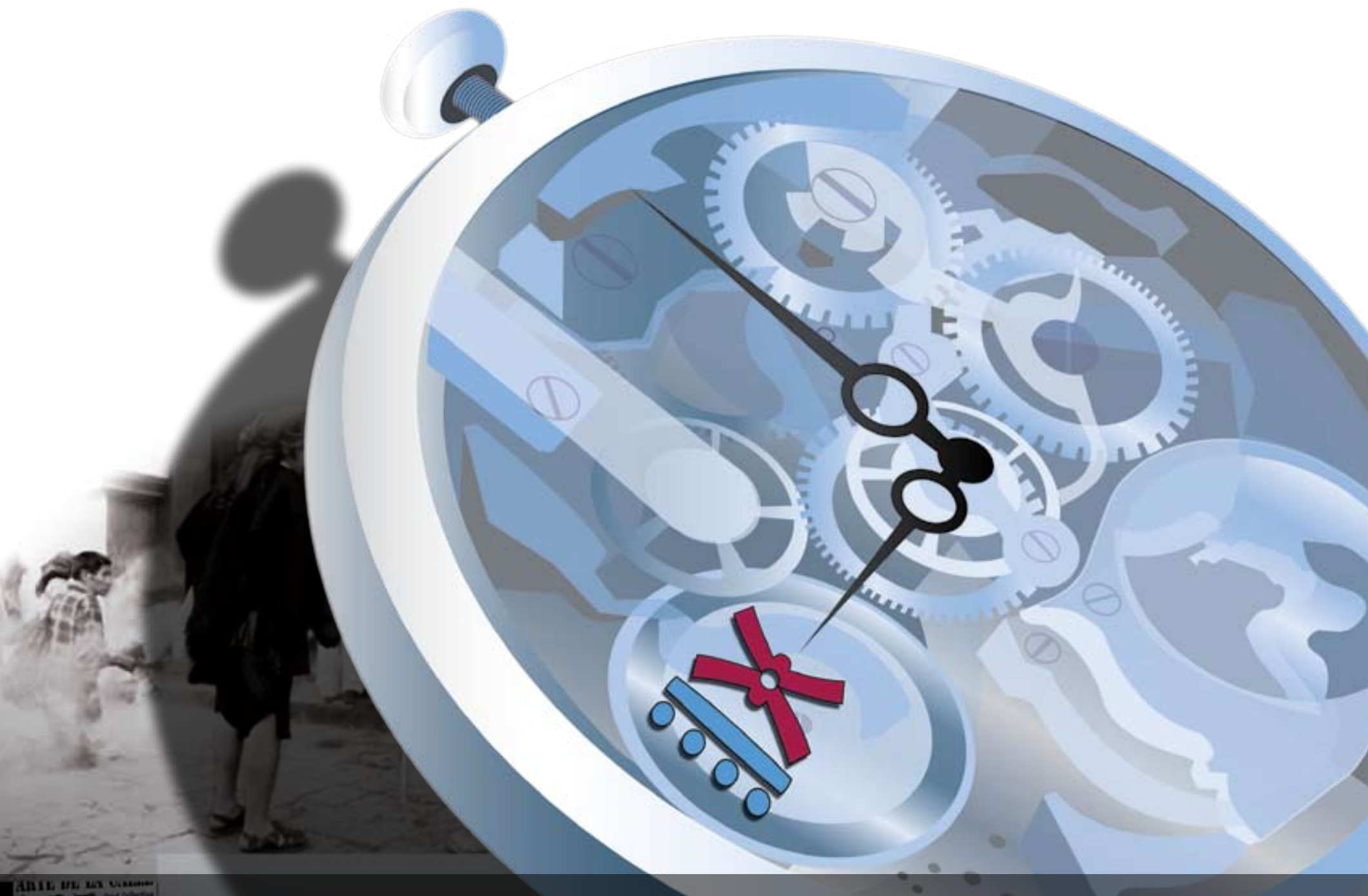

$9^{\circ}$ C O N G ESO 2. CENTROAMERICANO DE HISTORIA
ISSN 1409-469X

Fecha de recepción: 15 de mayo 2008 Fecha de aceptación: 30 de mayo 2008

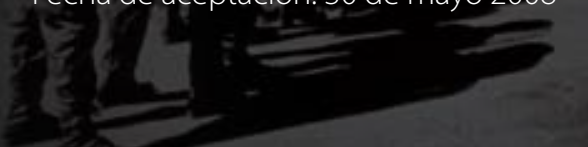

Alternativas de la memoria: revisiones del pasado y presente desde la ficción en la narrativa breve de mujeres guatemaltecas contemporáneas

Miembros del Consejo Editorial:

Dr. Ronny Viales, Dr. Juan José Marín

Editores Técnicos:

Allan Fonseca, Andrés Cruz, Gabriela Soto

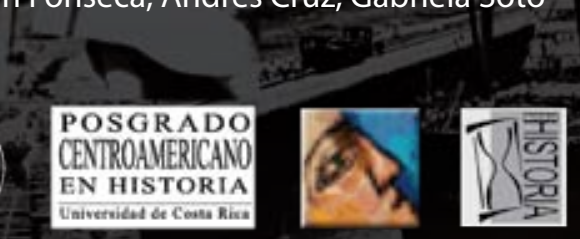


Indexaciones: Repositorio de Revistas UCR, DIALNET, Latindex, REDALYC Directorio y recolector de recursos digitales del Ministerio de Cultura de España, Directory of Open Access Journals. Diálogos Revista Electrónica de Historia ISSN 1409-469X. Número especial 2008. Dirección web: http://historia.fcs.ucr.ac.cr/dialogos.htm

\title{
Alternativas de la memoria: revisiones del pasado y presente desde la ficción en la narrativa breve de mujeres guatemaltecas contemporáneas
}

\author{
Guillermina Walas ${ }^{1 *}$
}

$1 \quad$ * Guillermina Walas es Profesora Visitante en la Universidad de Wisconsin, Madison (EEUU), en el Departamento de Español y Portugués. Recibió su doctorado de la Universidad de Pittsburgh (EEUU) en 1999 con especialización en literatura latinoamericana. Ha publicado Entre dos Américas. Narrativas de latinas en los '90s (crítica literaria-2000) y Fecundiciclos (poesía-2006) y numerosos artículos sobre testimonio, autobiografía y literatura escrita por mujeres.

Direcciones de correo electrónico: walas@wisc.edu; guiyermin@hotmail.com 


\section{Introducción}

La conexión entre memoria, historia e imaginación es innegable en el discurso historiográfico de Occidente como por ejemplo lo estudió Paul Ricoeur, entre otros, y dicha disciplina va reconociendo desde los ' $80 \mathrm{~s}$ el cruce con lo literario (desde los escritos de Hayden White principalmente). ${ }^{2}$ Sin embargo, en los intentos de diálogo, restauración, conciliación de las partes socio-políticas involucradas frente a crímenes de lesa humanidad como los cometidos en países como Guatemala durante casi cuarenta años (o en el Cono Sur, en El Salvador o en Sudáfrica, para mencionar algunos casos) se pretende que la memoria de quienes padecieron hechos por demás traumáticos se desligue de toda subjetividad y por ende, de las imágenes personales que parten del proceso memorialista. Así, géneros como el testimonio, por su contrato de verdad y su asociación con el discurso legal son susceptibles a las críticas de quienes todavía buscan que disciplinas como la historia o la antropología sean una ciencia exacta y la memoria una cámara objetiva.

Entonces, con el surgimiento de posturas que restringen el lugar y rol del testimonio en el campo histórico, antropológico y literario latinoamericano, ${ }^{3}$ se hace preciso reconsiderar

2 Ver, por ejemplo, Paul Ricoeur, Memory, History, Forgetting (Chicago-Londres: The University of Chicago Press, 2004); Hayden White, El texto histórico como artefacto literario y otros escritos (Madrid: Paidós, 2003); o la monumental obra en tres volúmenes dirigida por Pierre Nora, Le lieux de mémoire (Paris: Gallimard, 1992), donde la historia nacional o con mayúsculas queda indiscutiblemente ligada a los lugares y momentos privados, subjetivos, de la memoria.

3 Estas posturas comienzan, tal vez, desde la disciplina de la historia con el tan publicitado texto de David Stoll (Rigoberta Menchú and the Story of All Poor Guatemalans. Boulder, CO: Westview Press, 1999), o aún antes desde la literatura, donde el testimonio ha peleado por un espacio desde el establecimiento del género como categoría para el premio Casa de las Américas. Específicamente en el Cono Sur en los últimos años surgen cuestionamientos sobre la validez de la memoria testimonial precisamente por su cruce con lo literario y subjetivo. Para ejemplo de esto último vale mencionar el texto crítico de Beatriz Sarlo, Tiempo Pasado Cultura de la memoria y giro subjetivo. Una discusión (Buenos Aires: Siglo XXI, 2005) que 
otros espacios narrativos, específicamente literarios, que sin intención proclamada de representación veraz, tocan desde la ficción también fibras íntimas de la memoria colectiva y ofrecen versiones alternativas, a partir de las cuales se conforma un rompecabezas polifónico que, reconfigurado e interpretado en sus códigos, puede llevar a una imagen más amplia y completa de las tensiones socio-culturales en juego a la hora del revisionismo.

En este trabajo nos detendremos en esas piezas literarias, específicamente en las narrativas breves producidas por mujeres guatemaltecas en la posguerra o periodo posterior a la firma de los Acuerdos de Paz (1996). En efecto, tras la publicación de Mariana en la Tigrera (1996) de Ana María Rodas, ${ }^{4}$ se abre un nuevo espacio narrativo en Guatemala, dado que el cuento aparecía hasta entonces como un género restringido al exclusivo dominio masculino, y por lo tanto, también así lo estaban las versiones "ficcionales" de la historia - valga el aparente oxímoron - o, en otras palabras, las posibilidades de representar la realidad desde un punto de vista alternativo, tal como lo ofrece la literatura. A partir de la colección de Rodas, este panorama comienza a cambiar. Por ejemplo, consideramos que tanto Pezóculos (2001) de Aída Toledo como Mal de ojo (en prensa) de Patricia Cortez, entre otras colecciones de escritoras de la posguerra, ${ }^{5}$ dan testimonio - si jugamos un poco con los términos - de las alternativas presenta la polémica en torno a la idea de tomar el testimonio como forma literaria y a la vez como discurso de completa veracidad. Además, sorprendentemente, Sarlo también cuestiona la validez de la memoria testimonial para alcanzar la reconciliación cultural, lo cual es, sin duda, tocar un punto álgido de debate en Latinoamérica.

4 Ana María Rodas, Mariana en la tigrera (Guatemala: Editorial Artemis-Edinter, 1996). Para un análisis crítico de esta colección remito a: Angel Briones-Barco "Mariana insatisfecha en la tigrera melodramática" y a Guillermina Walas, "Mariana en la tigrera o la reversibilidad del nombrar", ambos en Aída Toledo, editora, Desde la zona abierta. Artículos críticos sobre la obra de Ana María Rodas (Guatemala: Palo de Hormigo, 2004), 145-161 y 187-200, respectivamente.

5 Toledo, Aída. Pezóculos. Guatemala: Palo de Hormigo, 2001. Todas las citas remitirán a esta edición. Respecto de la colección de Patricia Cortez, la misma está en prensa por una editorial guatemalteca. Trabajo con el manuscrito generosamente facilitado por una colega y 
de revisión memorialista que presenta la ficción así como de su capacidad reconstructiva del colectivo desde la apuesta perspicaz por la ambigüedad e ironía latente en toda representación.

\section{Pezóculos: visiones de ficción, memoria y verdad nadando con legado feminista}

Señala Jacques Derrida, al reflexionar sobre el testimonio y la ficción, que si tomamos dos discursos idénticos, autodenominándose uno serio y no ficcional, y el otro, por el contrario, propiamente literario y ficcional, es este último el más "verdadero", el que no puede ser acusado de falso o de mentir de ninguna manera. ${ }^{6}$ Leyendo constructivamente estas ideas deconstruccionistas derridianas a propósito de Maurice Blanchot, se podría entender que es en la ficción, al estar ésta desligada de la responsabilidad de cumplir estrictamente con la verdad (como ocurre en el caso del testimonio y su riesgo de perjurio) donde la misma se hace asequible. La visión subjetiva de quien escribe/narra, al no ponerse deliberadamente bajo el juicio de conjurar la verdad, llega a un atisbo de ella, e incluso a penetrar en las zonas más recónditas de lo no-dicho de la historia. En tal sentido, la colección de Aída Toledo, Pezóculos - un texto reciente y el primero de narrativas de la autora -, se entreteje como ficción en base a memorias fragmentarias ancladas en una realidad concreta, posiblemente en la infancia, adolescencia y proceso de maduración de su condición de mujer y sexualidad por parte de la autora, pero que surgen ahora elaboradas desde una subjetividad adulta. Por lo tanto, remiten directa o indirectamente a una época de particular violencia: la gestación y primeras décadas de la guerra civil guatemalteca que de manera abrupta lleva a ciertas redefiniciones del rol de la mujer: en especial, la empuja a dejar el espacio silencioso asignado tradicionalmente por el la paginación remitirá al mismo. Vale la pena mencionar además que hay otras colecciones de narrativa breve en prensa tales como Ir perdiendo de Gloria Hernández, también de próxima aparición a través de una editorial guatemalteca, y el espacio para este género que ahora proporciona la red. Haré referencia luego a algunos de los blogs de Patricia Cortéz como ejemplo de ello.

$6 \quad$ Jacques Derrida, Demeure. Maurice Blanchot (París: Galilée, 1998), 42. 
patriarcado para atestiguar, quiera o no, sobre los abusos del mismo.

$\mathrm{Al}$ respecto, en un informe de 1968 (época que coincide con la temprana adolescencia de Toledo), ya se reconocen y denuncian las atrocidades de las cuales las mujeres principalmente eran víctimas de diversas formas, incluso en la obligación aterrorizada de callar en el momento de la agresión. Sin embargo, en este informe muchos de los reportes surgen de voces femeninas: madres, hermanas, hijas, vecinas que han sido testigos de eventos brutales. ${ }^{7}$ Así, por ejemplo, yendo a la ficción, en el cuento "La coleccionista", la narradora comienza dirigiéndose a "Uds.", es decir incluyéndonos como lectores, en referencia a algo que por demás sabemos y que le hacía pensar a la protagonista "que sí, que siendo mujer había aprendido a tener miedo de todo, hasta de lo muy secreto". ${ }^{8}$ Sin embargo, continúa su empresa más allá de cualquier miedo y obtenemos el relato de una niña que "colecciona" deditos que encuentra en el cementerio donde visita la tumba de su abuela y que va usando "según sus necesidades". ${ }^{9}$ Su actividad la transforma, la fortalece, aún cuando se entera de que sus "piezas de colección" son el fruto de brutales crímenes. ${ }^{10}$ Otro relato, "El paralelo no viene al caso", representa las tensiones que conviven dentro y fuera del sujeto femenino y feminista que debe desdoblarse, travestirse o disfrazar su sexo ya sea para sobrevivir, ya para cumplir cierta misión que le ha sido asignada (“...ni hombre ni mujer para pasar desapercibida en tiempos

$7 \quad$ Comité de Defensa de los Derechos Humanos. La violencia en Guatemala. México: Fondo de Cultura Popular, 1968. 65, 142 y 152,153, en particular.

8 Toledo, 30.

$9 \quad$ Ibid., 31

10 La conexión entre muerte, coleccionismo, miedos y la figura de la abuela (su influencia, su memoria) reaparece en varios de los relatos, pero es sobre todo fuerte en éste y en el último fragmento de la narrativa entrecortada y epigramática que le da nombre a toda la colección, "Pezóculos"; dicho fragmento cierra el libro de la siguiente manera: “... y en cada ocasión la abuela colecciona más hombres para ser guardados dentro de esta ficción, en donde el humo, imita a la niebla, el pozo imita a la vida y la niña imita a la abuela" Ibid., 58. 
peligrosos para las mujeres." ${ }^{11}$ lo que la lleva aparentemente a "descabellados" paralelos que tal vez hacen al develamiento de la cruda realidad de la violencia. ${ }^{12}$

Además de ser una innegable memoria del ambiente de terror de una extensa y compleja guerra, las narrativas están ligadas a una visión política particular: la perspectiva de género. El carácter de legado feminista en Pezóculos se hace evidente desde la dedicatoria a la hija (bajo clave: el apodo íntimo y cariñoso de "Mema") y sobre todo en el epígrafe, de la chilena Diamela Eltit, que refiere a la auto-motivación de la mujer, su capacidad de crear por sí misma, en base al recuerdo y a su cuerpo que genera, entre otras cosas, palabras, incluso cuando se esté "trepada" al cuerpo del otro, haciéndole creer o jugando a que es gracias al otro que ella genera un discurso. ${ }^{13}$ Pero no: es ella, sujeto activo, movilizada por sus propias palabras y memorias, agente de cambio. Este doblez al que alude la cita de Eltit y que también está dado en el título de varias maneras, revela el juego irónico del texto tanto como su carácter trasgresor: podemos leer ingenua o superficialmente y aún notar que se trata de una reafirmación del ser femenino que contrarresta cualquier subordinación, incluso cuando la simule. Estas breves narrativas, agrupadas en dos secciones (una de cuentos individuales y

\section{$11 \quad$ Ibid., 43}

12 El paralelo termina "viniendo al caso" en tanto se refiere claramente a tácticas de represión contrainsurgente y de desaparición durante la guerra civil, de la que se estima un saldo de 45 mil desaparecidos y 200 mil asesinados. Informe de la Comisión para el Esclarecimiento Histórico, Guatemala. Memoria del silencio (Guatemala: F\&G Editores, 1999 y versión en red http://shr.aaas.org/guatemala/ceh/mds/spanish/). También, respecto a la represión y abusos basados en el género, tanto "El paralelo no viene al caso" como en otros relatos ("Perpetuos Horror" y "Adiós Adiós", por ejemplo) encuentran su contexto documentado extensamente en testimonios como los recopilados por el Consorcio Actoras de Cambio, Rompiendo el silencio. Justicia para las mujeres víctimas de violencia sexual durante el conflicto armado en Guatemala (Guatemala: ECAP-UNAMG-F\&G editores, 2006).

13 Ibid., epígrafe. Cito: "Trepo encima tuyo entibiada por mis recuerdos, movilizada por mis propias palabras." 
otra de diez fragmentos muy breves que componen propiamente "Pezóculos") nos hablan de la capacidad de auto-representación y generación de una voz, de una tradición que es otra que la patriarcal, a partir de la cual se trata de escapar de los roles de víctima y victimario paradójicamente mostrando que no hay escape sino sólo la posibilidad de juego satírico entre ambas casillas.

La sexualidad es una zona clave para hablar de los intersticios de la historia y las posibilidades de la ficción para entenderlos. Como señala Diane Marting al referirse a la novelística de las últimas décadas, la literatura (y específicamente la latinoamericana) se ha visto transformada por la manera en que los temas sexuales han sido expresados por las autoras-mujeres y asimismo, tales temas son inseparables de otras cuestiones políticas, por lo cual la contextualización en el caso latinoamericano es indispensable. ${ }^{14}$ Así, la enunciación en Pezóculos se produce desde una sexualidad desafiante de los silencios a los que la subjetividad ha sido sometida tal vez por su género, pero no exclusivamente por ello. Entonces, el lenguaje sexuado y sexual supone aquí una forma rebelión contra el autoritarismo, por ejemplo, o contra la represión dada por las normas de un sistema rígido, pero también la que resulta de la marginación por raza, clase o cualquier diferencia respecto de la subjetividad normada y hegemónica. Esto permite a las voces de Pezóculos - todas femeninas - ser portadoras de una versión alternativa de la historia, tanto por remitir a una realidad indiscutiblemente guatemalteca (incluso cuando el escenario del relato no es Guatemala) desde una zona de ficción, como por hacerlo también desde voces no escuchadas aún o escuchadas "a medias", sólo para ser silenciadas o negadas después como versiones falsas. ${ }^{15}$ Sin duda, la perspectiva 14 Martings, Diane. "Dangerous (To) Women: Sexual Fiction in Spanish America" en Narrativa femenina en América Latina. Prácticas y perspectivas teóricas, ed. Sara Castro-Klarén (Madrid-Frankfurt: Iberoamericana-Vervuert, 2003), 199 y 216.

15 Me refiero claramente a casos tan famosos como el testimonio de Rigoberta Menchú Tum (Elizabeth Burgos Debray, Me llamo Rigoberta Menchú y así me nació la conciencia. 
de género para revisar memoria e historia desde la ficción es indispensable en un país como Guatemala, donde se sabe que "a la mujer se le mata por el simple hecho de serlo" y el feminicidio es visto como un claro "factor cultural". ${ }^{16}$

Por último, a diferencia de lo que sucede con la poesía de Toledo que es mucho más lúdica, casi socarrona en su tono, estas narrativas poseen un giro irónico más gris. En esa atmósfera pesadillezca de los textos breves de Pezóculos las figuras femeninas continuamente enfrentan el asedio de un patriarcado subyacente aún en ellas mismas. En "Cajita China", por ejemplo, la narradora concluye:

Bien se ve que estar en los bordes es un símbolo en este libro y en nuestras vidas, en donde una/otra mujer (como yo) que escribe, pierde el poder paulatinamente, asediada por un ente larva que la arrastra hasta los límites, en donde no le queda (no me queda) más que como una loba, aullarle a la luna. ${ }^{17}$

El "ente larva" y el "cíclope" son figuras que alegorizan el acoso a una subjetividad que se desdobla y desde el margen nos llama, en grito de denuncia, en un aullido, porque la lengua está bajo el hechizo de normas y mandatos profundamente enraizados en ella misma y que hacen que, como en su poemario más reciente, la lengua quede "pegada al paladar", paralizada.

La Habana: Casa de las Américas, 1983), que viniendo de una mujer maya adquirió increíble notoriedad (incluyendo un Premio Nobel de la Paz), pero asimismo se hizo foco de múltiples acusaciones, entre las cuales en el ámbito académico norteamericano se destaca el ya mencionado texto de David Stoll (nota 2) .

16 Son las declaraciones del procurador de Derechos Humanos de Guatemala, Sergio Morales Alvarado el 7 de mayo de 2007 a Alejandro Cano para el diario La opinión. Allí agrega que más del cincuenta por ciento de los crímenes actuales son contra mujeres y un catorce por ciento es a manos de grupos organizados. Alejandro Cano, "Las Heridas que no cierran en Guatemala", La opinión, 7 de mayo, 2007 http://www.laopinion.com/latinoamerica/?rkey=000 00000000001616080 (Fecha de acceso: 30 de marzo 2008)

Toledo, 25. 
Pero de tanto luchar logrará zafarse y, de a poco, articularse en discurso poético, narrativa, voz que se agencia de sus actos y su representación alternativa. ${ }^{18}$

Entonces, como señala Regina Schroeder en su introducción a los relatos, para contrarrestar las conductas de subordinación que proponen las narrativas canónicas del patriarcado, sobre todo aquellas que desde la literatura infantil moldean los roles de género, es necesario comenzar por releer y reescribir tales narrativas con un "gesto político", ${ }^{19}$ lo cual Toledo hace con maestría pero también, requiriendo de la sutileza de los lectores para interpretar la historia concreta que se esconde entre las líneas de la ficción.

\section{La “ojeada” realidad de la post-guerra en la prosa breve de Patricia Cortez:}

\section{contando con Mal de ojo ${ }^{20}$}

Desde sus blogs que refieren impresiones de lo cotidiano (más a la manera del testimonio ya que son opiniones firmadas sobre problemas sociales de la actualidad guatemalteca), ${ }^{21}$ tanto como desde sus cuentos (en prensa), Patricia Cortez pone a sus lectores virtuales en contacto con la realidad de una sociedad en ruinas y con subjetividades que, como en el caso de las narrativas de Pezóculos, viven y se desarrollan en los márgenes. De hecho, en la ficción los personajes de Cortez, portadores de memorias traumáticas, nos hacen percibir un 18 Aludo a la última colección de poesía de Toledo, Con la lengua pegada al paladar. (Guatemala: Ediciones del Cadejo y Centro Cultural Español de Guatemala, 2006).

19 Schroeder, Regina. "Introducción" a Toledo, Pezóculos, 13.

20 Juego aquí con el dicho popular de estar "ojeado" cuando alguien "nos ha echado" el llamado "mal de ojo".

21 "La falta de oportunidades ¿pretexto o no?”y "Mujeres”, por ejemplo, en el sitio Guatemalidades http://guatemaliness.blogspot.com/ (Fechas de acceso: 28 de febrero, 2008 y 21 de marzo, 2008). Es interesante notar que en uno de sus relatos en la colección Mal de ojo, "Mail to. Angustia"[sic], trata precisamente sobre la posibilidad de mentir, simular, engañar, inventar en la red, pero al leer los blogs firmados por la autora se observa la distancia crítica entre la ficción y el discurso de opinión, puesto que Cortez parece diferenciarse bastante de su personaje en el cuento (al menos tal es nuestra lectura) y hacerse cargo con mucha seriedad de lo que dice. 
país (no nombrado en la mayoría de los casos, aunque no por eso menos tangible), que ya sea por la guerra, la economía, las divisiones de clase y etnia, o todo ello (y algo más) combinado, se ha desarticulado, quebrado en un caos sin remedio aparente más que el giro imaginativo.

“Páginas amarillas" es uno de esos casos: nos presenta un personaje masculino, un hombre sin nombre en un lugar también anónimo, que acaba de cobrar en el banco sus últimos haberes. Caracterizado como emocionalmente perturbado y antisocial ("tiene mucho tiempo de no hablar con nadie"), ${ }^{22}$ se hace "víctima" de un mendigo o vendedor ambulante con el que intercambia su único billete por un directorio telefónico comercial, sólo por evitar su mirada y supuesto acoso. Al llegar a la casa, donde no le queda ni siquiera un teléfono (lo que hace más absurda la transacción), termina por discar imaginariamente un número ante el apremio del estómago. La comida a domicilio llega. Al día siguiente es el apremio de compañía el que acosa y ésta también llega, pero no se logra vencer la soledad. Ante las páginas amarillas, de las que los avisos y números anteriores han desaparecido, la mirada se detiene en un anuncio que promete "la verdad". Sin embargo, esa verdad parece ser la locura de un sujeto torturado, cuya historia jamás podría articularse de manera creíble. El relato se lee en definitiva como alegoría de una sociedad fragmentada y en ruinas en la que los sujetos son disfuncionales a causa de los traumas que provocan la soledad, el aislamiento, el miedo a ser desaparecido, a morir solo y acosado por fantasmas, entre otros taras que se derivan de una guerra prolongada o de situaciones de brutal inestabilidad socio-política y económica. ${ }^{23}$ "La llamada” y "La fuga" son relatos que también refieren a este mismo clima en que el sujeto está acosado y no hay una

22 Cortez, Mal de ojo, 1

23 Entre otros textos periodísticos, de no-ficción, que servirían para contextualizar y lamentablemente "confirmar" la realidad que presentan estos relatos desde la literatura, remito a Edelberto Torres-Rivas, “Inermes?¿Atrapados, sin salida?” en Cuadernos del presente imperfecto. Las izquierdas, Rigoberta Menchú, la historia (Guatemala: F\&G Editores, 2007), 45-47. 
escapatoria más que, irónicamente, la muerte o la locura. Además, la irrupción de la tecnología (sobre la que giran varios de los cuentos), no parece ayudar sino alienar más a los sujetos y crear divisiones todavía más pronunciadas en el colectivo.

Por otra parte, aunque a diferencia de Pezóculos, las perspectivas narrativas, sobre todo en lo que hace al género, parezcan más variadas, es curioso notar que los relatos que se enuncian desde la primera persona en la colección de Cortez también lo hacen desde un marcado feminismo. "Las mujeres en las manifestaciones", por ejemplo, es una rememoración irónica sobre las desigualdades de género en la política de los 60s y 70s (y que no hace falta decir que aún se dan), y que las mujeres afrontaban con candorosa inocencia. El relato comienza con la enigmática frase "Éramos siempre: feas", ${ }^{24}$ lo que podría pensarse como una apreciación superficial sobre estética. En cambio, en el transcurso de la narrativa, vemos que el adjetivo no tiene que ver solamente con un patrón de belleza, sino que va transformándose desde "fea" igual a "despreocupada por la imagen" a "dominada, usada o abusada por el varón”. Como la mayoría de los relatos de Cortez, éste nos deja también con un escenario de pérdida y en el medio de un juego ambiguo de binarios (feas versus bonitas, políticas versus apolíticas, profesionales versus amas de casa, etc.). Sin embargo, no importa el lado en que se esté. Si se es mujer, la afirmación "éramos siempre: feas" en definitiva significa "siempre llevamos las de perder, antes y ahora, no importa lo que hagamos". En cuanto a la historia con mayúsculas, el relato es un darse cuenta precisamente del uso o manipuleo de las mujeres que, hagan lo que hagan, no alcanzan a ser sujetos de la misma.

Otro cuento que enfoca en el género y es una denuncia explícita del patriarcado, "Nacimientos", narra en primera persona desde la perspectiva de una joven. ${ }^{25}$ La narradora

$24 \quad I b i d ., 25$.

25 Ibid. 15-17. 
observa desde el recuerdo (puesto que es evidente que está contado desde la reminiscencia) la bigamia de su padre y cómo al aliarse con su madre en brujerías, fue testigo del desprecio de su condición de hija-mujer. La madre era despreciada por tener solo niñas, por una parte aunque seguía siendo víctima esporádica de los acosos del marido y teniendo hijos de ese hombre con cierta ilusión (cada vez más débil) de que un hijo varón le devolvería la fidelidad y el amor de pareja. Pero la hija, ignorada como sus hermanas, relata esta historia en la que todos parecen perder: la madre incluso teniendo un varón no logra recuperar al esposo, la amante se vuelve loca al parir una hija, y así y todo, paradójicamente, el hombre se queda con ella. La hija mayor y sus hermanas continúan ignoradas y sólo la hija ilegítima o de la "otra" es la reconocida en lo concreto. Este es uno de los pocos relatos que aún con su negatividad y denuncia, nos deja cierto mensaje esperanzado porque a pesar de la tristeza desde la que se narra el abandono paterno, conlleva la idea de que el varón también puede enamorarse y la mujer también puede jugar con las mismas tácticas del cuerpo y la sexualidad (se insinúa sobre el final que el hijo varón no era del padre) que el varón usa para someterla.

Para concluir esta sección sobre Patricia Cortez podríamos regresar a la observación de Derrida: si se contrastan las narrativas de los blogs firmados por la autora y las de la colección de ficción, todas ellas comparten una misma estética y visión de la realidad guatemalteca actual y del legado traumático de la guerra en la memoria colectiva. Sin embargo, es evidente que las primeras, por estar firmadas y pertenecer a los códigos del discurso de opinión, generan un cuestionamiento similar al del testimonio. En su último blog del 24 de marzo, 2008, titulado "Náusea y espanto", Cortez nos dice:

...este es el último post que escribo, dentro de unos días voy a borrar del mapa este blog. El asco es demasiado. Por donde comenzar?[sic] Podría ser por la realidad 
nacional, el hecho de que de nuevo hablar de justicia social y de solidaridad es un discurso "peligroso" que lo coloca a uno en el papel de "agitador" y demás bellezas. $^{26}$

Reconociendo el carácter más "peligroso" del discurso de no ficción, con su ironía característica, la autora se despide. Aunque, quienes sabemos de sus cuentos, entendemos dicha despedida de la opinión firmada como la afirmación de que no queda otra salida que la misma voz, pero bajo el velo de la condición propiamente literaria para evitar ser "ojeado" y luego derrotado por el público hegemónico, que por otra parte es el que en países como Guatemala tiene acceso casi exclusivo a la red. Luego, como en la colección de Toledo, la imagen predominante, explícita, es la del horror nauseabundo que atrapa al sujeto y de alguna manera lo aniquila en la impotencia de modificar la situación vigente:

...la verdad es que mi nausea es real, y que si sigo escribiendo voy a terminar mal, como decían en los 80 y siguen diciendo "esa anda metida en babosadas".

Este texto electrónico de no-ficción refuerza tal vez la hipótesis que hemos aquí esbozado: la única alternativa que le queda al sujeto no hegemónico que firma intentando representar auténticamente su visión de realidad tanto como su percepción memorialista es la ficción, porque irónicamente aunque parezca contada bajo los hechizos del "mal de ojo", ésta es la que devela la mirada más lúcida del pasado y presente guatemalteco.

\section{Conclusión}

Por último, si siguiendo lo señalado por Diane Nelson sobre agencia cultural en Guatemala tenemos en cuenta el rol prostético de la postulación esencialista o estereotípica de la figura de la mujer guatemalteca, sobre todo en su versión “étnica", como "mujer

26 Patricia Cortez, "Náusea y espanto" (http://guatemaliness.blogspot.com/ Acceso: 29 de marzo). 
maya" en el proceso de pacificación y reconstrucción de post-guerra desde el testimonio y la historiografía, ${ }^{27}$ la importancia de la perseverancia y aumento de las voces de mujer, ya sea desde géneros de ficción o no, desde la literatura, el performance y otras manifestaciones artísticas, se hace aún más relevante en el refuerzo de una historia alternativa a la de los grupos dominantes o, para decirlo de otra manera, a las versiones hegemónicas.

Los textos observados, si bien recurren a la ficción como estrategia para narrar - tal vez lo inenarrable - son representaciones claras de la vivencia de la guerra tanto como de las cicatrices que permanecen hoy (a más de diez años de la firma de los Acuerdos de Paz) en la sociedad guatemalteca. De tal manera, presentando imágenes del caos de hoy (la postguerra con su aguda crisis socio-económica y la violencia entre sectores de una sociedad dividida) las breves narrativas nos proyectan las pesadillas del ayer; tratan de reír por no llorar ante la destrucción que ha traído la historia reciente del país y finalmente, reconstruyen imaginativamente para hacernos ver, con o sin "mal de ojo", lo que de otra manera quedaría en las reincidencias del olvido.

27 Diane M. Nelson, "The Cultural Agency of Wounded Body Politic: Ethnicity and Gender as Prosthetic Support in Postwar Guatemala", ed. Doris Sommer, Cultural Agency in the Americas (Durham-Londres: Duke University Press, 2006), 109. Ese rol prostético se ve en el mencionado texto de Edelberto Torres-Rivas, ya desde el título del reporte. 